\title{
Impact of specialist follow-up in outpatients with congestive heart failure
}

\author{
Justin A. Ezekowitz, Carl van Walraven, Finlay A. McAlister, Paul W. Armstrong, Padma Kaul
}

ß See related article page 207

\section{Abstract}

Background: There is uncertainty about whether physician specialty influences the outcomes of outpatients with congestive heart failure after adjustment for differences in case mix. Our objective was to determine the impact of physician specialty on outcomes in outpatients with new-onset congestive heart failure.

Methods: The study was a population-based retrospective cohort study involving patients with new-onset congestive heart failure discharged from 128 acute care hospitals in Alberta between Apr. 1, 1998, and July 1, 2000. Outcomes were resource utilization (clinic visits, emergency department visits and hospital admissions) and survival at 30 days and 1 year.

Results: A total of 3136 patients were discharged from hospital with a new diagnosis of congestive heart failure (median age 76 years, 50\% men). Of these, 1062 (34\%) received no follow-up visits for cardiovascular care, 738 (24\%) were seen by a family physician (FP) alone, 29 (1\%) by a specialist (cardiologist or general internist) alone and 1307 (42\%) by both a specialist and an FP. Compared with patients who received no follow-up cardiovascular care, patients who received regular cardiovascular follow-up visits with a physician had fewer visits to the emergency department (38\% v. 80\%), fewer were admitted to hospital (13\% v. 94\%), and the adjusted 1-year mortality was lower (22\% v. 37\%) (all $p<$ 0.001). Compared with patients who received combined specialist and FP care, patients cared for exclusively by FPs had fewer outpatient visits (median 9 v. 17 in the first year), fewer of these patients presented to the emergency department ( $24 \%$ v. $45 \%$ in the first year), and fewer were readmitted for cardiovascular care ( $7 \%$ v. $16 \%$ ) (all $p<0.001)$. However, the adjusted mortality at 1 year was lower among patients treated with combined care $(17 \%$ v. $28 \%, p<0.001)$ despite a higher burden of comorbidities. In a multivariate model adjusting for comorbidities (with no cardiovascular follow-up visits as the reference category), the mortality was lower among patients followed on an outpatient basis by an FP alone (odds ratio [OR] 0.66, 95\% confidence interval [CI] $0.53-0.82$ ) or by an FP and a specialist (OR 0.34, 95\% CI $0.28-0.42$ ). In a proportional hazards model with timedependent covariates (with adjustment for frequency of follow-up visits), the risk of all-cause mortality was reduced significantly (hazard ratio $0.98,95 \% \mathrm{Cl} 0.97-0.99$ ) with each specialist visit compared with FP care alone.
Interpretation: Patients with congestive heart failure followed by both specialists and FPs had significantly better survival than those followed by FPs alone (or those who received no specific cardiovascular follow-up care). Methods to improve timely and appropriate access to specialists and to improve collaborative care structures are needed.

CMAJ 2005;172(2):189-94

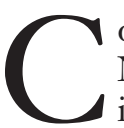
ongestive heart failure (CHF) afflicts up to $2 \%$ of North American adults and, despite many advances in diagnosis and therapy, still portends a poor prognosis, with 1 -year mortality of $30 \%-50 \% \cdot{ }^{1-5}$ Although the prognosis of patients with CHF is poor even with optimal management, suboptimal diagnosis, investigation and treatment of heart failure and comorbidities (e.g., coronary artery disease) in community-dwelling patients contributes to poor survival..$^{6-9}$

In previous studies hospital inpatients with $\mathrm{CHF}$ who were cared for by specialists received more evidence-based therapies and had better outcomes than those cared for by nonspecialists. ${ }^{8,10-13}$ However, none of these studies examined the care delivered after discharge from hospital. Although management in specialized multidisciplinary clinics is associated with better outcomes, ${ }^{14}$ it is unclear whether similar benefits can be expected when patients are cared for by specialist physicians operating outside the setting of a multidisciplinary clinic. Two recent studies from the United States that reported better outcomes with specialist care ${ }^{7,15}$ were flawed, in that neither study adjusted for frequency of outpatient visits or the possibility of time-dependent bias ${ }^{16}$ (whereby some variables, including the number of visits, will change over time).

To address this important public health issue, we sought to determine whether there is a relation between ambulatory care follow-up and outcomes in patients with new-onset CHF.

\section{Methods}

We linked 4 databases maintained by Alberta Health and Wellness, which record individual patient interactions with the health care system in Alberta: the Discharge Abstract Database, which records information (including dates, diagnoses and procedures) on all admissions to any of 128 acute care facilities; the Ambulatory 
Care Database, which tracks all visits to hospital-based physicians' offices and about 100 emergency departments; the Physician Claims Database, which tracks all claims for service (by diagnostic code) made by physicians for the outpatient care of patients in about 5000 physicians' offices; and the Alberta Health Care Insurance Registry, which tracks the vital status of all 3.1 million Albertans. ${ }^{17,18}$ Outpatient cardiovascular visits were identified as those with International Classification of Diseases, 9th revision, clinical modification (ICD-9CM) codes 390-459 as the most responsible diagnosis.

We used the Discharge Abstract Database to identify all Alberta residents who had been admitted to hospital at least once between Apr. 1, 1998, and July 1, 2000, with a most responsible diagnosis of CHF (ICD-9-CM code 428.0) and established a cohort of incident cases by excluding patients who had been admitted because of $\mathrm{CHF}$ in the preceding 5 years. The accuracy of our data acquisition and the use of discharge coding to identify cases and comorbidities have been described elsewhere. ${ }^{17}$ Patient comorbidities were also determined from the Discharge Abstract Database, which records up to 16 premorbid or complicating conditions. We characterized hospitals as "urban" if they were located in health regions servicing the populations of Edmonton or Calgary $(n=20)$; all others were characterized as "rural" $(n=108)$. Charlson Index comorbidity scores were calculated by the method of Deyo and associates, ${ }^{19}$ and income was determined by the neighbourhood postal code (Forward Sortation Area) system available from Statistics Canada.

We followed all patients from the date of discharge from the index hospital admission until they died or until Mar. 31, 2001 (whichever came first). Follow-up was 100\%. We restricted our analyses to all-cause mortality or readmission for cardiovascular reasons only (any of ICD-9-CM codes 390-459 as the most responsible diagnosis). The primary outcome measure was 1-year mortality; we hypothesized that the 1-year mortality would be lowest (after adjustment for important covariates) among patients followed by a specialist.

The Ambulatory Care and Physician Claims databases record the specialty of each physician who submits claims. Of the 236 specialists in Alberta who submitted claims for cardiovascular diagnoses during the study period, 202 worked in urban regions and 34 in rural areas. Patients with no ambulatory care claims for a cardiovascular diagnosis after their discharge from an acute care facility were classified as having no cardiovascular claims, those seen solely by a family practitioner (FP) were classified as having received FP care, those seen solely by an internist or a cardiologist were classified as having received specialist care, and those seen by both an FP and a specialist were classified as having received combined care if there was at least 1 claim from a physician in each group. Patients who received FP, specialist or combined care constituted the cohort with "any cardiovascular claims."

We summarized baseline descriptive data in terms of percentages for categorical variables and medians with interquartile ranges for continuous variables. The $\chi^{2}$ test and the Kruskal-Wallis test were used to compare characteristics across groups. We used Kaplan-Meier analysis to examine unadjusted survival patterns across patient groups.

To adjust for differences in baseline characteristics and important covariates between groups, we performed multivariate logistic regression using a backward, stepwise method for 30-day and 1 -year outcomes, entering all variables with $p<0.25$ on bivariate analysis into the model (including all variables in Table 1). Multi-

Table 1: Baseline characteristics of patients with congestive heart failure

\begin{tabular}{|c|c|c|c|c|c|c|}
\hline \multirow[b]{2}{*}{ Characteristic } & \multicolumn{2}{|c|}{$\begin{array}{l}\text { Cardiovascular claims; } \\
\% \text { of patients* }\end{array}$} & \multirow[b]{2}{*}{$p$ value } & \multicolumn{2}{|c|}{$\begin{array}{l}\text { Type of care; } \\
\% \text { of patients* }\end{array}$} & \multirow[b]{2}{*}{$p$ value } \\
\hline & $\begin{array}{c}\text { None } \\
n=1062\end{array}$ & $\begin{array}{l}\text { At least one } \\
n=2074\end{array}$ & & $\begin{array}{l}\text { FP only } \\
n=738\end{array}$ & $\begin{array}{c}\text { Combined } \\
n=1307\end{array}$ & \\
\hline \multicolumn{7}{|l|}{ Sociodemographic } \\
\hline Age, yr, mean (SD) & $76(11)$ & $76(12)$ & 0.98 & $83(11)$ & $74(12)$ & $<0.001$ \\
\hline Male & 50 & 47 & 0.07 & 41 & 49 & $<0.001$ \\
\hline $\begin{array}{l}\text { Household income, } \$ \text {, median } \\
\text { (interquartile range) }\end{array}$ & $\begin{array}{c}44088 \\
(42 \quad 192-53 \quad 381)\end{array}$ & $\begin{array}{c}44957 \\
(42192-54986)\end{array}$ & 0.017 & $\begin{array}{c}44808 \\
(42330-53381)\end{array}$ & $\begin{array}{c}45337 \\
(41818-54896)\end{array}$ & 0.02 \\
\hline Urban & 43 & 50 & $<0.001$ & 36 & 57 & $<0.001$ \\
\hline \multicolumn{7}{|l|}{ Cardiovascular comorbidities } \\
\hline Ischemic heart disease & 35 & 30 & 0.003 & 25 & 33 & $<0.001$ \\
\hline Prior CABG & 4 & 2 & 0.003 & 1 & 3 & 0.036 \\
\hline Hypercholesterolemia & 5 & 5 & 0.46 & 2 & 6 & 0.001 \\
\hline Hypertension & 30 & 29 & 0.64 & 23 & 33 & $<0.001$ \\
\hline Peripheral vascular disease & 6 & 4 & 0.06 & 3 & 4 & 0.25 \\
\hline \multicolumn{7}{|l|}{ Other comorbidities } \\
\hline Diabetes mellitus & 24 & 19 & 0.001 & 15 & 21 & 0.001 \\
\hline Cerebrovascular disease & 4 & 3 & 0.31 & 4 & 3 & 0.73 \\
\hline Chronic renal insufficiency & 8 & 5 & 0.002 & 4 & 5 & 0.11 \\
\hline Anemia & 18 & 16 & 0.27 & 16 & 16 & 0.74 \\
\hline Malignant disease & 4 & 6 & 0.05 & 7 & 5 & 0.14 \\
\hline COPD & 23 & 25 & 0.24 & 22 & 27 & 0.012 \\
\hline $\begin{array}{l}\text { Charlson Index, median } \\
\text { (interquartile range) }\end{array}$ & $1.2(0-2)$ & $1.1(0-2)$ & 0.002 & $1.0(0-1)$ & $1.1(0-2)$ & 0.006 \\
\hline
\end{tabular}

Note: $\mathrm{SD}=$ standard deviation, $\mathrm{FP}=$ family physician, $\mathrm{CABG}=$ coronary artery bypass grafting, $\mathrm{COPD}=$ chronic obstructive pulmonary disease.

*Unless stated otherwise 
ple logistic regression analyses were run to determine which factors were associated with patient death. Statistical significance was accepted at $p<0.05$, and all first-order interactions were tested.

A time-dependent analysis is essential when examining the effect of physician follow-up because patients' outcomes can determine their exposure (e.g., patients may die before having the opportunity to attend a follow-up visit). We therefore performed a Cox proportional hazard regression with time-dependent covariates to determine whether specialist visits after discharge from hospital were associated with a lower risk of all-cause mortality. Fixed covariates included in the model were those significantly $(p<0.1)$ associated with time to death in a backward-stepping Cox model that included only fixed covariates. Postdischarge interactions with the health care system were expressed as timedependent variables, including cumulative number of cardiovascular visits, cumulative number of cardiovascular visits with a specialist and cumulative number of days in hospital. These timedependent variables were added to a Cox model containing the significant fixed covariates. All cardiovascular visits (i.e., the number of visits) were included in the model as a measure of overall illness (i.e., sicker patients tend to see physicians more frequently). Proportionality assumptions for the Cox model were tested with both the goodness-of-fit test and log-minus-log test and were met for all analyses.

In a sensitivity analysis, we used patients without any outpatient visits for any diagnosis after discharge as the reference group for the logistic and Cox models.

This study was approved by the Health Research Ethics Board of the University of Alberta.

\section{Results}

We identified 3466 patients with an index admission for new-onset CHF between 1998 and 2000; the 3136 (90\%) who survived the index hospital admission represented the cohort for this study. Compared with patients who were discharged alive, patients who died during the index hospital stay had higher rates of ischemic heart disease $(46 \% \mathrm{v}$. $34 \%)$, chronic renal disease (22\% v. $6 \%)$, anemia ( $25 \%$ v. $16 \%)$, malignant disease (11\% v. 6\%) and cerebrovascular disease ( $9 \%$ v. $4 \%)$. The median length of stay was 7 days (interquartile range 4-11), and 58\% (2015) of the $3466 \mathrm{pa}-$ tients with new-onset $\mathrm{CHF}$ were treated in the 10 Alberta hospitals that had more than $100 \mathrm{CHF}$-related admissions in the study period. During the index admission, $48 \%$ of the patients $(n=1490)$ were treated by FPs, $21 \%(n=653)$ by general internists, $8 \%(n=257)$ by cardiologists and $23 \%(n=736)$ by other physicians.

In the year after the index admission, 34\% of the patients $(n=1062)$ did not see any physician who reported a cardiovascular diagnosis as the reason for the visit ("no cardiovascular claims"). Twenty-four percent $(n=738)$ had a cardiovascular diagnosis reported by an FP alone, 1\% (29) had a cardiovascular diagnosis reported by a specialist alone, and $42 \%(n=1307)$ were seen by both a specialist and an FP for a cardiovascular diagnosis ("combined care").

Compared with patients who received combined care, those seen exclusively by FPs were older, more likely to be female, more likely to live in a rural setting and less likely to have ischemic heart disease, hypertension, diabetes mellitus or chronic obstructive pulmonary disease (Table 1). Charlson Index comorbidity scores were higher among patients who received combined care than among those seen solely by FPs $(p=0.006)$; patients with no cardiovascular claims had higher Charlson Index comorbidity scores than patients who had at least 1 cardiovascular outpatient visit $(p=0.002)$.

Median household income was significantly different across all 3 groups $(p<0.02)$; patients who received combined care had the highest income (median $\$ 45337$, interquartile range $\$ 41$ 818-\$54 896) (Table 1).

Within the first year, more of the patients who received no cardiovascular follow-up visits after discharge than of the patients who saw a physician for an outpatient cardiovascular visit had visits to the emergency department $(80 \%$ v. $38 \%, p<0.001)$ and more were admitted to hospital for cardiovascular reasons $(94 \%$ v. $13 \%, p<0.001)$; unadjusted mortality rates were also higher among those with no cardiovascular follow-up (7\% v. $2 \%$ at 30 days, $33 \%$ v. $20 \%$ at 1 year) (Table 2). Patients without cardiovascular follow-up visits also presented to the emergency department or were admitted to hospital sooner than patients with cardiovascular follow-up visits. Of patients who had a physician visit for a cardiovascular diagnosis, those cared for by FPs had fewer outpatient visits than those who received combined care (median 9 v. 17 in the first year), fewer of these patients had visits to the emergency department ( $24 \%$ v. $45 \%)$, and fewer were readmitted for cardiovascular reasons $(7 \%$ v. $16 \%)$ (all $p<0.001)$. However, FPtreated patients who presented to the emergency department did so earlier than patients who received combined care (median 63 days v. 95 days, $p<0.001$ ). Among the patients who received combined care, the median number of ambulatory visits to a specialist was 3 (interquartile range $1-7)$, and $16 \%$ of these patients received over half of their postdischarge care from a specialist.

The 30-day and 1-year mortality rates differed significantly between patients who received treatment exclusively from FPs and those who received combined care from an FP and a specialist (Table 2 and Fig. 1, unadjusted survival $\log$-rank $=61, p<0.001)$. For the 1 -year unadjusted survival analysis, the group with no cardiovascular claims had a higher mortality than the FP-treated group (log-rank $=6.5$, $p=0.01)$ and the group treated by combined care (log-rank $=131.4, p<0.001)$. Similarly, in the unadjusted survival analysis using all claims rather than cardiovascular claims, the group who did not receive any follow-up care had a lower survival rate than the FP-treated group (log-rank = $57.0, p<0.001)$ and the group treated by combined care $(\log$-rank $=110.3, p<0.001)$.

The results for the multivariate logistic regression model for 1-year mortality are outlined in Table 3. Patients who were followed as outpatients by an FP or by both a specialist and an FP for cardiovascular diagnoses had better 
survival than patients for whom no cardiovascular claims were made. The adjusted odds ratios were virtually identical in the sensitivity analyses when patients with no outpatient claims were used as the reference group.

When a Cox proportional hazards time-dependent covariate model was used to adjust for differing follow-up periods and frequency of follow-up visits, higher age, diabetes mellitus, ischemic heart disease, cerebrovascular disease, peripheral vascular disease, renal failure, malignant disease and cumulative days spent in hospital within 1 year after discharge from the index admission were all associated with a higher mortality rate. Female sex and seeing a specialist as an outpatient (hazards ratio 0.98 per visit to specialist, 95\% confidence interval 0.97-0.99]) were associated with lower mortality.

\section{Interpretation}

Patients discharged after their first hospital stay for heart failure had better outcomes (fewer emergency department visits, fewer readmissions to hospital and lower mortality rates) if they received regular cardiovascular follow- up visits with a physician; those who saw both an FP and a specialist had the most comorbidities but the lowest mortality rates. Perhaps as a reflection of the higher disease burden in these patients, we found that resource use (hospital admissions, emergency department visits) was greatest for patients followed by both a specialist and an FP.

Why did outcomes differ by care provider? Patients cared for by both a specialist and an FP have more contacts with the medical community; thus, there are more opportunities for deterioration in status to be detected, for medications to be added or titrated, or for the nonpharmacologic therapies that are important in $\mathrm{CHF}$ to be reinforced. Other studies of myocardial infarction and CHF have shown greater prescribing of proven efficacious therapies by specialists than by generalist physicians..$^{11,12,17,20,21}$ Certainly, a wealth of practice audit data have confirmed that angiotensin-converting-enzyme inhibitors, $\beta$-blockers and spironolactone are underused and underdosed in CHF patients who are cared for in the community. ${ }^{6,9,17}$ Indeed, differences in outcomes have been seen for many diseases when care is provided by specialists or generalist physicians. ${ }^{22-24}$ Although specialty heart failure clinics have been

Table 2: Resource utilization by patients with congestive heart failure after discharge from index hospital admission

\begin{tabular}{|c|c|c|c|c|c|c|}
\hline \multirow[b]{2}{*}{ Characteristic } & \multicolumn{2}{|c|}{$\begin{array}{l}\text { Cardiovascular claims; } \\
\text { median (and IQR)* }\end{array}$} & \multirow[b]{2}{*}{$p$ value } & \multicolumn{2}{|c|}{$\begin{array}{l}\text { Type of care; median (and } \\
\text { IQR)* }\end{array}$} & \multirow[b]{2}{*}{$p$ value } \\
\hline & $\begin{array}{c}\text { None } \\
n=1062\end{array}$ & $\begin{array}{l}\text { At least one } \\
n=2074\end{array}$ & & $\begin{array}{l}\text { FP only } \\
n=738\end{array}$ & $\begin{array}{c}\text { Combined } \\
n=1307\end{array}$ & \\
\hline \multicolumn{7}{|l|}{ Ambulatory care } \\
\hline Days to first cardiovascular claim & NA & $7(3-13)$ & NA & $7 \quad(4-14)$ & $6 \quad(3-12)$ & $<0.001$ \\
\hline \multicolumn{7}{|l|}{ Cardiovascular claims } \\
\hline No. in 30 days & NA & $2(1-4)$ & NA & $2(1-3)$ & $3(2-4)$ & $<0.001$ \\
\hline No. in $1 \mathrm{yr}$ & NA & $14(8-23)$ & NA & $9 \quad(5-16)$ & $17(11-26)$ & $<0.001$ \\
\hline \multicolumn{7}{|l|}{ Any claims $†$} \\
\hline No. in 30 days & $3(1-4)$ & $3(2-4)$ & 0.028 & $2(1-4)$ & $3(2-5)$ & $<0.001$ \\
\hline No. in $1 \mathrm{yr}$ & $19(10-30)$ & $16(9-26)$ & $<0.001$ & $10(5-17)$ & $19(13-30)$ & $<0.001$ \\
\hline \multicolumn{7}{|l|}{ Acute care } \\
\hline $\begin{array}{l}\% \text { with emergency department } \\
\text { visits in } 1 \mathrm{yr}\end{array}$ & 80 & 38 & $<0.001$ & 24 & 45 & $<0.001$ \\
\hline $\begin{array}{l}\text { Days to first emergency } \\
\text { department visit }\end{array}$ & $65(18-162)$ & $90(22-195)$ & $<0.001$ & $63(13-169)$ & $95(27-214)$ & $<0.001$ \\
\hline $\begin{array}{l}\% \text { with cardiovascular } \\
\text { readmission in } 1 \mathrm{yr}\end{array}$ & 94 & 13 & $<0.001$ & 7 & 16 & $<0.001$ \\
\hline $\begin{array}{l}\text { Days to first cardiovascular } \\
\text { readmission }\end{array}$ & $69(19-162)$ & $160(73-295)$ & $<0.001$ & 157 (46-265) & 163 (81-299) & 0.33 \\
\hline \multicolumn{7}{|l|}{ Mortality, \% } \\
\hline \multicolumn{7}{|l|}{ 30-day } \\
\hline Unadjusted & 7 & 2 & $<0.001$ & 4 & $<1$ & $<0.001$ \\
\hline Adjusted $\neq$ & 10 & 3 & $<0.001$ & 5 & $<1$ & $<0.001$ \\
\hline \multicolumn{7}{|l|}{$1-y r$} \\
\hline Unadjusted & 33 & 20 & $<0.001$ & 28 & 14 & $<0.001$ \\
\hline Adjusted§ & 37 & 22 & $<0.001$ & 28 & 17 & $<0.001$ \\
\hline
\end{tabular}


shown to improve outcomes and are ubiquitous in most academic centres in North America, ${ }^{25,26}$ only a minority of heart failure patients are followed in these multidisciplinary clinics. ${ }^{14}$ Thus, our finding that patients who see both a specialist and their FP have better outcomes is particularly encouraging.

There are limitations to any study that uses data from an administrative database. The key limitation of this study was the lack of information on functional status, severity of CHF, revascularization and medication use. However, we restricted our analysis to patients who had been admitted to hospital with a primary diagnosis of $\mathrm{CHF}$, virtually all of whom would have had class III or IV symptoms. ${ }^{27} \mathrm{We}$ relied upon discharge coding to identify both the most responsible diagnosis and the comorbidities. Previous studies have confirmed the accuracy of our data source for cardiovascular conditions, particularly CHF. ${ }^{28-30}$ Furthermore, although the use of ICD-9-CM code 428 likely underestimates the prevalence of heart failure, it is a highly specific marker for $\mathrm{CHF}$, and we are confident that the patients we identified did have heart failure. ${ }^{29}$ Most patients have at least 1 hospital admission within 2 years of identification of their heart failure; we extended our exclusion period to 5 years, thus ensuring that our cohort consisted of incident cases of new-onset CHF.

Finally, it is impossible in an observational study to exclude the possibility that unmeasured confounders not captured in the administrative databases may have accounted for the differences in outcomes between the

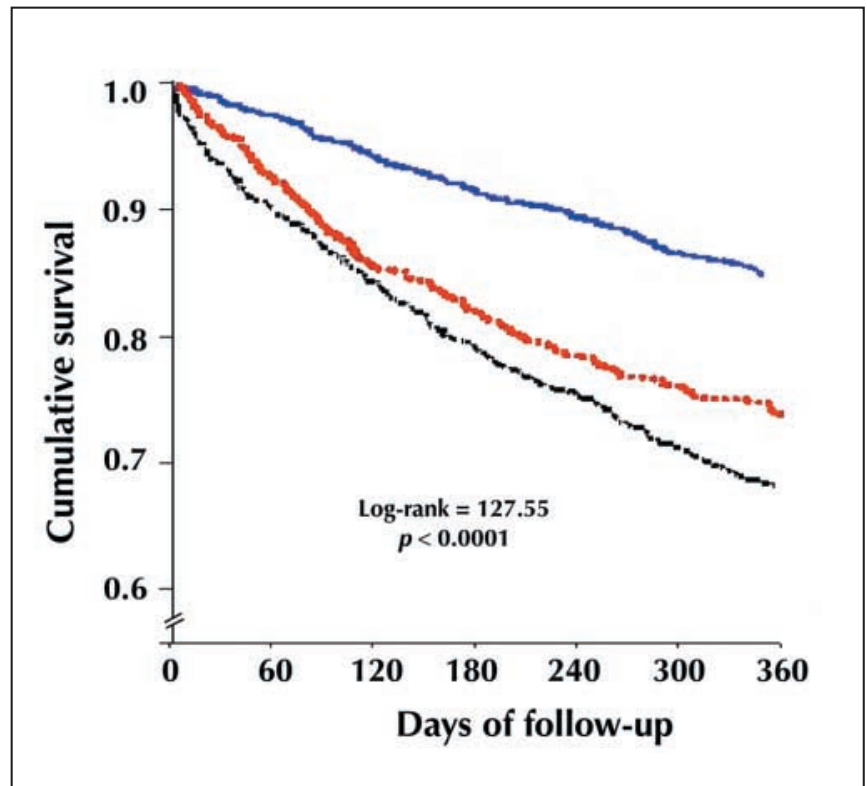

Fig. 1: Kaplan-Meier survival curves for care received, by ambulatory specialty. Blue line $=$ combined care (both specialist and family physician), red line = care by family physician only, black line = no cardiovascular claims (i.e., no physician visits for a cardiovascular cause). groups. However, we did collect substantial data on comorbidities and we believe that by restricting our analysis to incident cases of CHF and adjusting for length of initial hospital stay along with other comorbidities (including readmissions and frequency of clinic visits), we have minimized the possibility that there were important clinical differences between the groups we examined. Notably, we were not able to adjust for revascularization rates directly, but we did adjust for hospital readmissions in the multivariate logistic regression and Cox proportional hazards models (because coronary artery bypass grafting, stenting and angioplasty in a patient with CHF would be done in the hospital setting). A trial in which patients were randomly assigned to different types of physicians would be the only means to conclusively determine how best to follow CHF patients, but such a trial would be impossible to conduct, because it would be unethical to assign a sicker patient to see an FP alone if they needed combined care and access to the diagnostic resources of a specialist, such as coronary angiography.

Patients with CHF living in the community are at high risk for early and late death, and the risk is greatest among those who do not receive regularly scheduled medical care after discharge. Outpatient care involving both an FP and a specialist is associated with a $66 \%$ reduction in the risk of 1 -year mortality, even after adjustment for differences in comorbidities, visit frequency and length of follow-up. Our data suggest that methods to improve timely and appropriate access to specialty care are needed, and patients with new-onset $\mathrm{CHF}$ are at particular risk for early adverse outcomes if appropriate care is not delivered.

This article has been peer reviewed.

From the Division of Cardiology (Ezekowitz, Armstrong, Kaul) and the Division of General Internal Medicine (McAlister), University of Alberta, Edmonton, Alta.; and the Department of Medicine, University of Ottawa, Ottawa, Ont. (van Walraven).

Competing interests: None declared

Table 3: Unadjusted and adjusted odds ratios (ORs) for 1-year mortality

\begin{tabular}{lccc}
\hline & \multicolumn{3}{c}{ OR (95\%Cl) } \\
\cline { 2 - 5 } Variable & Unadjusted & Adjusted \\
\hline Age $>65 \mathrm{yr}$ & $1.68(1.49-1.90)$ & $1.64(1.44-1.87)$ \\
Female & $0.90(0.76-1.06)$ & 0.81 & $(0.68-0.97)$ \\
Hypertension & $0.83(0.69-1.00)$ & 0.81 & $(0.67-0.99)$ \\
Peripheral vascular disease & $1.67(1.17-2.39)$ & 1.54 & $(1.05-2.26)$ \\
Malignant disease & $3.74(2.72-5.14)$ & 3.99 & $(2.83-5.62)$ \\
Renal failure & $1.82(1.34-2.48)$ & 1.67 & $(1.20-2.34)$ \\
Cerebrovascular disease & $1.78(1.29-2.47)$ & 1.62 & $(1.15-2.29)$ \\
Anemia & $1.55(1.27-1.90)$ & 1.30 & $(1.05-1.62)$ \\
FP only* & $0.76(0.62-0.93)$ & 0.66 & $(0.53-0.82)$ \\
FP and specialist* & $0.33(0.27-0.41)$ & 0.34 & $(0.28-0.42)$ \\
\hline
\end{tabular}

Note: $\mathrm{Cl}=$ confidence interval.

*Patients with no cardiovascular claims as reference group. 
Contributors: Justin Ezekowitz, Finlay McAlister and Paul Armstrong contributed to the conception and design of the study. All of the authors contributed to analysis and interpretation of the data. Carl van Walraven and Padma Kaul provided statistical expertise. Justin Ezekowitz, Finlay McAlister, Paul Armstrong and Padma Kaul drafted the article, and all of the authors provided critical revision for important intellectual content. All of the authors gave their final approval of the article submitted.

Acknowledgements: We thank Cynthia Yau for her assistance with data management and statistical support. Justin Ezekowitz is a Canadian Institutes of Health (CIHR) Strategic Training Fellow in TORCH (Tomorrow's Research Cardiovascular Health Professionals). Finlay McAlister is a Population Health Investigator of the Alberta Heritage Foundation for Medical Research and a New Investigator of the CIHR. Carl van Walraven is a Career Scientist of the Ontario Ministry of Health and Long-Term Care. None of the funding agencies had input into the design, conduct, analysis or reporting of this study.

\section{References}

1. American Heart Association. 2002 heart and stroke statistical update. Dallas: The Association; 2002.

2. Cowie MR, Mosterd A, Wood DA, Deckers JW, Poole-Wilson PA, Sutton GC, et al. The epidemiology of heart failure. Eur Heart 7 1997;18(2):208-25.

3. Heart and Stroke Foundation of Canada. The changing face of heart disease and stroke in Canada. Ottawa: The Foundation; 2000.

4. Redfield MM, Jacobsen SJ, Burnett JC Jr, Mahoney DW, Bailey KR, Rodeheffer RJ. Burden of systolic and diastolic ventricular dysfunction in the community: appreciating the scope of the heart failure epidemic. FAMA 2003;289:194-202.

5. Jong P, Vowinckel E, Liu PP, Gong Y, Tu JV. Prognosis and determinants of survival in patients newly hospitalized for heart failure: a population-based study. Arch Intern Med 2002;162:1689-94.

6. Cleland JG, Cohen-Solal A, Aguilar JC, Dietz R, Eastaugh J, Follath F, et al; IMPROVEMENT of Heart Failure Programme Committees and Investigators. Improvement programme in evaluation and management; Study Group on Diagnosis of the Working Group on Heart Failure of the European Society of Cardiology. Management of heart failure in primary care (the IMPROVEMENT of Heart Failure Programme): an international survey. Lancet 2002;360:1631-9.

7. Indridason OS, Coffman CJ, Oddone EZ. Is specialty care associated with improved survival of patients with congestive heart failure? Am Heart 72003 145:300-9.

8. Philbin EF, Weil HF, Erb TA, Jenkins PL. Cardiology or primary care for heart failure in the community setting: process of care and clinical outcomes. Chest 1999; $116: 346-54$

9. Stafford RS, Radley DC. The underutilization of cardiac medications of proven benefit, 1990 to 2002. 7 Am Coll Cardiol 2003;41:56-61.

10. Auerbach AD, Hamel MB, Davis RB, Connors AF Jr, Regueiro C, Desbiens $\mathrm{N}$, et al. Resource use and survival of patients hospitalized with congestive heart failure: differences in care by specialty of the attending physician. SUPPORT Investigators. Study to Understand Prognoses and Preferences for Outcomes and Risks of Treatments. Ann Intern Med 2000;132(3):191-200.

11. Jong P, Gong Y, Liu PP, Austin PC, Lee DS, Tu JV. Care and outcomes of patients newly hospitalized for heart failure in the community treated by cardiologists compared with other specialists. Circulation 2003;108:184-91.

12. Bellotti P, Badano LP, Acquarone N, Griffo R, Lo Pinto G, Maggioni AP, et al. Specialty-related differences in the epidemiology, clinical profile, management and outcome of patients hospitalized for heart failure; the OSCUR study. Oucome dello Scompenso Cardiaco in relazione all'Utilizzo delle Risore. Eur Heart 7 2001;22(7):596-604.

13. Krumholz HM, Parent EM, Tu N, Vaccarino V, Wang Y, Radford MJ, et al. Readmission after hospitalization for congestive heart failure among Medicare beneficiaries. Arch Intern Med 1997;157(1):99-104.

14. McAlister FA, Lawson FM, Teo KK, Armstrong PW. A systematic review of randomized trials of disease management programs in heart failure. Am $7 \mathrm{Med}$ 2001;110:378-84.
15. Ansari M, Alexander M, Tutar A, Bello D, Massie BM. Cardiology participation improves outcomes in patients with new-onset heart failure in the outpatient setting. 7 Am Coll Cardiol 2003;41:62-8.

16. Van Walraven C, Davis D, Forster AJ, Wells GA. Time-dependent bias was common in survival analyses published in leading clinical journals. 7 Clin Epidemiol 2004;57(7):672-82.

17. Sin DD, McAlister FA. The effects of beta-blockers on morbidity and mortality in a population-based cohort of 11942 elderly patients with heart failure. Am 7 Med 2002;113:650-6.

18. Chang WC, Kaul P, Westerhout CM, Graham MM, Fu Y, Chowdhury T, et al. Impact of sex on long-term mortality from acute myocardial infarction vs. unstable angina. Arch Intern Med 2003;163(20):2476-84.

19. Deyo RA, Cherkin DC, Ciol MA. Adapting a clinical comorbidity index for use with ICD-9-CM administrative databases. 7 Clin Epidemiol 1992;45:613-9.

20. Chen J, Radford MJ, Wang Y, Krumholz HM. Care and outcomes of elderly patients with acute myocardial infarction by physician specialty: the effects of comorbidity and functional limitations. Am 7 Med 2000;108:460-9.

21. McAlister FA, Teo KK, Taher M, Montague TJ, Humen D, Cheung L, et al Insights into the contemporary epidemiology and outpatient management of congestive heart failure. Am Heart 7 1999;138(1 Pt 1):87-94.

22. Greenfield S, Kaplan SH, Kahn R, Ninomiya J, Griffith JL. Profiling care provided by different groups of physicians: effects of patient case-mix (bias) and physician-level clustering on quality assessment results. Ann Intern Med 2002;136:111-21.

23. Kitahata MM, Koepsell TD, Deyo RA, Maxwell CL, Dodge WT, Wagner EH. Physicians' experience with the acquired immunodeficiency syndrome as a factor in patients' survival. N Engl 7 Med 1996;334:701-6.

24. Wu AW, Young Y, Skinner EA, Diette GB, Huber M, Peres A, et al. Quality of care and outcomes of adults with asthma treated by specialists and generalists in managed care. Arch Intern Med 2001;161(21):2554-60.

25. Hunt SA, Baker DW, Chin MH, Cinquegrani MP, Feldman AM, Francis GS, et al; American College of Cardiology/American Heart Association Task Force on Practice Guidelines (Committee to Revise the 1995 Guidelines for the Evaluation and Management of Heart Failure); International Society for Heart and Lung Transplantation; Heart Failure Society of America. ACC/AHA guidelines for the evaluation and management of chronic heart failure in the adult: executive summary. A report of the American College of Cardiology/American Heart Association Task Force on Practice Guidelines (Committee to Revise the 1995 Guidelines for the Evaluation and Management of Heart Failure): developed in collaboration with the International Society for Heart and Lung Transplantation; endorsed by the Heart Failure Society of America. Circulation 2001;104:2996-3007.

26. Liu P, Arnold M, Belenkie I, Howlett J, Huckell V, Ignazewski A, et al; Canadian Cardiovascular Society. The 2001 Canadian Cardiovascular Society consensus guideline update for the management and prevention of heart failure. Can 7 Cardiol 2001;17(Suppl E):5E-25E.

27. Philbin EF, Rocco TA Jr, Lindenmuth NW, Ulrich K, Jenkins PL. Clinical outcomes in heart failure: report from a community hospital-based registry. Am 7 Med 1999;107:549-55.

28. Naylor D, Slaughter P, editors. Cardiovascular health and services in Ontario: an ICES atlas. Toronto: Institute for Clinical Evaluative Sciences; 1999. p. 25-30.

29. Goff DC Jr, Pandey DK, Chan FA, Ortiz C, Nichaman MZ. Congestive heart failure in the United States: Is there more than meets the I(CD code)? The Corpus Christi Heart Project. Arch Intern Med 2000;160:197-202.

30. Austin PC, Daly PA, Tu JV. A multicenter study of the coding accuracy of hospital discharge administrative data for patients admitted to cardiac care units in Ontario. Am Heart 7 2002;144:290-6.

Correspondence to: Dr. Paul W. Armstrong, 2-51 Medical

Sciences Building, University of Alberta, Edmonton $A B$

T6G 2H7; fax 780 492-9486; paul.armstrong@ualberta.ca 